\title{
GITEPen 5 urteko esperientzia Gipuzkoan: diziplina anitzeko taldea biriketako tronboenbolismo akutu larriaren artatze integralerako
}

\author{
Five Year Experience of the Gipuzkoa Pulmonary Embolism Response Team \\ (GITEP) in the Basque Country
}

\begin{abstract}
Karlos Reviejo Jaka ${ }^{2}$, Marta Iriarte Ibarraran ${ }^{1}$, Maria Pascal Jimenez ${ }^{1}$, Gabriel Txoperena Altzugarai ${ }^{1}$, Iñaki Arcega Fernandez ${ }^{1}$, Felix Zubia Olaskoaga ${ }^{1}$, Txoan Ormazabal Zabala ${ }^{1}$, Xoan Sanmartín Pena ${ }^{3}$, Garikoitz Lasa Larraya ${ }^{4}$, Mariano Larman Tellechea ${ }^{5}$, Iñaki Salegi Etxebeste $^{6}$, Iñaki Royo Gutiérrez ${ }^{6}$, Alberto Sáenz Bermejillo ${ }^{7}$, Juan José Goiti Unibaso ${ }^{7}$, Iñigo Lozano Martínez-Luengo ${ }^{8}$
\end{abstract}

Donostia Unibertsitate Ospitaleko Zainketa Intentsiboen Unitatea ${ }^{1}$ Policlínica Gipuzkoako Zainketa Intentsiboen Unitatea ${ }^{2}$

Santiagoko Unibertsitate Ospitale Klinikoko Kardiologia Interbentzionistako Zerbitzua ${ }^{3}$

Donostia Unibertsitate Ospitaleko Kardiologia Interbentzionistako Zerbitzua ${ }^{4}$

Policlínica Gipuzkoako Kardiologia Interbentzionistako Zerbitzua - QuirónSalud5 ${ }^{4}$

Donostia Unibertsitate Ospitaleko Pneumologia Zerbitzua ${ }^{6}$

Policlínica Gipuzkoako Bihotzeko Kirurgiako Zerbitzua - QuirónSalud ${ }^{7}$

Cabueñes Ospitaleko Kardiologia Interbentzionistako Zerbitzua. Gijón ${ }^{8}$

kreviejo@gmail.com,marta.iriarteibarraran@osakidetza.eus

\section{Laburpena}

Sarrera: 2012ko urtarrilean GiTEP diziplina anitzeko taldea eratu zenbiriketako tronboenbolismo akutu larriaren tratamendurako, Gipuzkoan, 800.000 biztanleko eremuan. Helburua prozesu honetan inplikatutako zerbitzuen arteko koordinazioa hobetzea zen, erantzun azkarrago, aktiboago, osoago eta indibidualizatuago bat emanaz.

Material eta metodoak: GiTEPek barne hartzen ditu medikuntza intentsiboko, kardiologia interbentzionistako, bihotzeko kirurgiako, pneumologiako, erradiodiagnostikoko, erradiologia interbentzionistako, larrialdietako, hematologiako eta onkologiako espezialistak. 2012ko urriaren eta 2016ko abenduaren artean ingresatutako pazienteen ezaugarri demografikoak, tratamendua eta lehen 6 hilabeteetako bilakaera aztertu ziren.

Emaitzak: Denbora-tarte horretan 178 paziente ingresatu ziren biriketako tronboenbolismoagatik Gipuzkoako zainketa intentsiboen unitateetan, European Society of Cardiologyren 2014ko sailkapenaren arabera estratifikatuta. Horietatik, 124 pazientetan (\% 70) aktibatu zen GiTEPKodea, eta horien artean 35 arrisku handikoak eta 89 arrisku ertain-altukoak izan ziren. Batez besteko adina 65 urtekoa izan zen, eta \% 50,6 gizonak izan ziren. Gehien erabili zen tratamendua antikoagulazioa izan zen $(\% 57,3)$. Birperfusio aurreraturako, kateter bidez gidatutako teknika farmakoinbasiboa $(\% 28,1)$ eta rtPA bidezko fibrinolisi sistemikoa $(\% 12,4)$ erabili ziren. Ez zen inor ebakuntza bidez tratatu. \% 6,7k konplikazio hemorragikoak izan zituen, bat bera ere ez bizi-arriskukoa edo intrakraneala. ZIUko egonaldiaren mediana 3 egunekoa izan zen, eta ospitalekoarena 9 egunekoa. 30 egunerako hilkortasuna\% 6,2koa izan zen. 
Eztabaida eta ondorioak: Biriketako tronboenbolismo larriaren diziplina anitzeko kudeaketak paziente hauen tratamendurako jarrera proaktiboago eta antolatuago bat ahalbidetu du, konplikazio hemorragiko larririk gabe eta espero baino hilkortasun txikiagoarekin.

Gako-hitzak: biriketako tronboenbolismoa, arriskuaren estratifikazioa, diziplina anitzeko taldeak, TEPKodea, kateter bidez gidatutako terapia farmakoinbasiboa, fibrinolisi sistemikoa

\section{Abstract}

Background: The GITEP multidisciplinary response team was created in January 2012 to provide the highest level of care to patients with severe pulmonary embolism in a region of 800,000 inhabitants. The aim of creating the team was to improve coordination between the services involved in the process, delivering a more streamlined, active, complete and personalised response.

Methods: the GITEP team is made up of specialists from Intensive Care, Interventional Cardiology, Cardiac Surgery, Pneumology, Radiology, Emergency Department, Haematology and Oncology. This paper analyses, in a prospective observational study, the demographic characteristics, treatment and progress of patients admitted between January 2012 and December 2016 over the first six months of treatment. Differences between ratios were analyzed using the $\chi^{2}$ method or Fisher's exact test and regression analysis was used to verify tendencies.

Results: 178 PE patients were admitted to Intensive Care and stratified according to the European Society of Cardiology 2014 classification. The GiTEP protocol was activated in 124 patients (70\% ), of which 35 were classified as high risk and 89 as intermediate-high risk. Mean age $=65$ years; $50.6 \%$ male. The most frequently administered treatment was anticoagulation (57.3\% ); the advanced reperfusion therapy of choice was catheter-directed therapy $(28.1 \%)$, followed by systemic thrombolysis with rtPA (12.4\% ). No surgery was performed. 6.7\%of patients experienced haemorrhagic complications, in no case life-threatening or intracranial. The median length of ICU stay was 3 days and of hospital stay was 9 days. The mortality rate at 30 days was $6.2 \%$.

Conclusion: Multidisciplinary intervention in severe pulmonary embolism has resulted in a more proactive, systematic treatment of patients in the region, with no serious haemorrhagic complications and a mortality rate lower than expected.

Keywords: pulmonary embolism; risk assessment; pulmonary embolism response team (PERT); pulmonary embolism code; catheter-directed therapy; systemic thrombolysis.

Bidalia: - 2020.10.23

Onartua: 2021.03.28

http://doi.org/10.26876/osagaiz.1.2021.230

\section{Sarrera}

Biriketako tronboenbolismoa (BTE) morbimortalitate altuko patologia da bere forma larrienetan. Fibrinolisi sistemikoa aukerako tratamendua den arren, birperfusioprimariorako indikazioa duten BTEdun paziente gehienak modu kontserbadorean artatzen dira oraindik ${ }^{(1,2)}$. Fibrinolisi sistemikoaren (FS)(1)hemorragia-arriskuak azal lezake gida klinikoen ez-betetze hau, bestelako aukerak proposatu direlarik; besteren artean, fibrinolisi sistemikoa dosi txikiagoekin, kateter bidez gidatutako terapia farmakoinbasiboa (K-TFI) edo gorputzez kanpoko zirkulazio bidez lagunduriko biriketako enbolektomia (E-GKZ).

Terapia horiek ebaluatzeko ikerketen gabezia eta BTE akutudun pazienteen maneiuaren zailtasuna dela eta, zenbait ospitaletan diziplina anitzeko taldeak sortu dira BTEaren tratamendurako, literatura internazionalean PERT deituak (Pulmonary Embolism Response Team) ${ }^{(1-6)}$. Talde horietako partaideak dira besteren artean, larrialdietako medikuak, intentsibistak, pneumologoak, 
erradiologoak (irudi bidezko erradiodiagnostikoa), kardiologoak (interbentzionistak eta ekografistak), bihotzeko kirurgialariak, onkologoak eta hematologoak, nahiz eta ospitale bakoitzaren arabera aldakuntzak izaten diren. PERThoriek BTE larriaren artatzearen kalitatea eta efikazia neurtzeko eredu moduan garatu dira. Horiek aktibatzean, espezialista ezberdinek simultaneoki aztertzen dute kasu bakoitza, tratamendu-aukerak balioetsi eta aholku azkarra emanez, terapia doitu bat koordinatzeko ${ }^{(2)}$. Helburua morbimortalitatea gutxitzea da, paziente bakoitzaren ezaugarriei egokitutako tratamendua erabiliz.

Artikulu honetan aurkezten ditugu Gipuzkoan BTE larria artatzeko diziplina anitzeko talde bat (GiTEP) sortzearen emaitzak.

\section{Material eta metodoak}

2012ko urtarriletik 2016ko abendura bitartean Gipuzkoako zainketa intentsiboen unitateetan BTE diagnostikoarekin ospitaleratutako pazienteen ikerketa obserbazional prospektiboa.

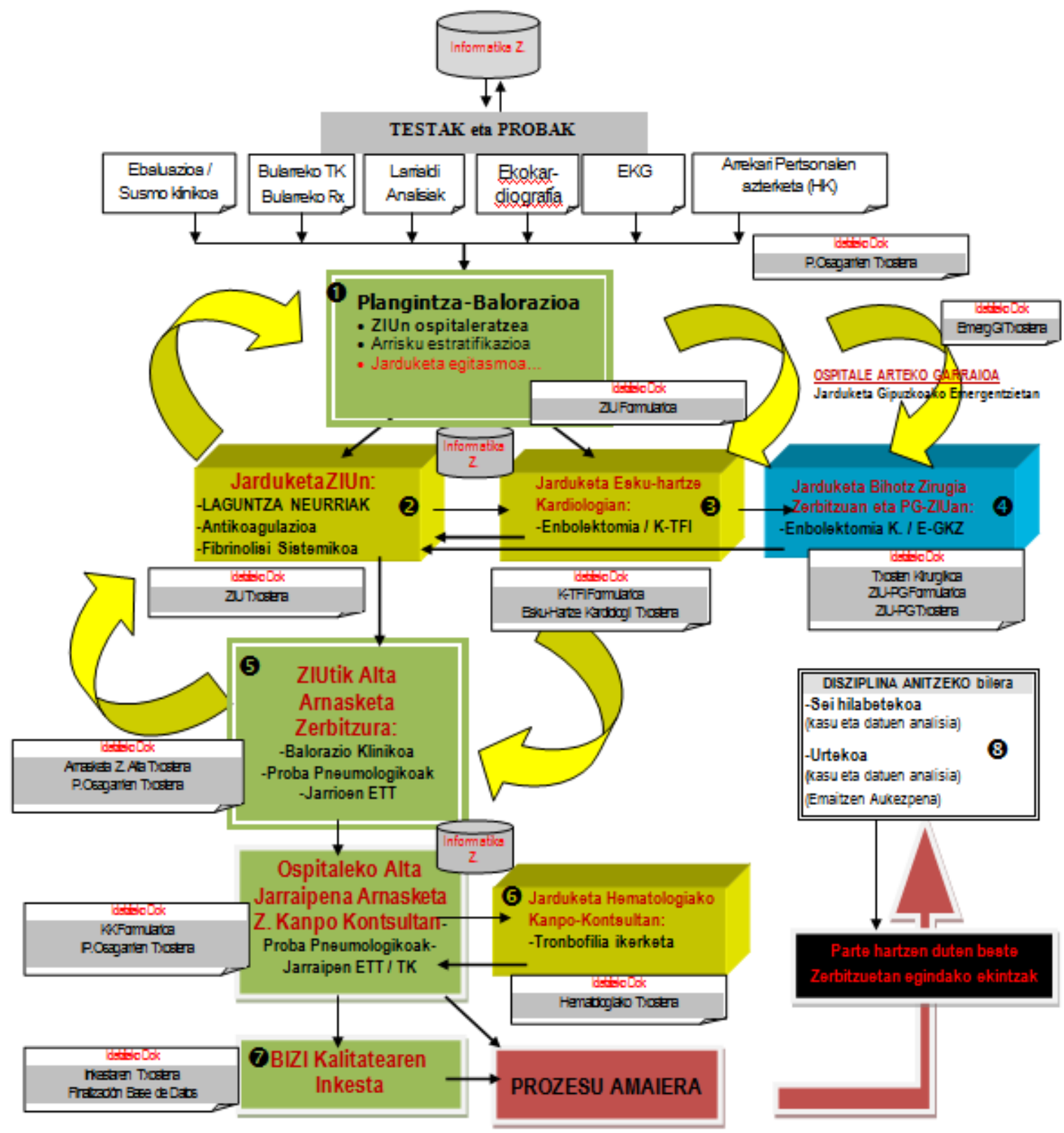

1. irudia. Prozesuaren fluxu-diagrama, ospitaleratzetik (larrialdiak eta ospitaleratze-solairuak) pneumologiako kontsultetatiko behin betiko alta eman arte. 


\section{GiTEP Protokoloa}

2012an ezarri ziren 800.000 biztanleko Gipuzkoan BTE larriaren artatzea optimizatuko zuen erantzun integraleko taldea (GiTEP) sortzeko oinarri eta akordio interdiziplinarrak. 1. irudian azaltzen da prozesuaren fluxu-diagrama.

Gure probintziako paziente larri guztiak Donostia Unibertsitate Ospitalera (DUO), inguruko hirugarren mailako zentro bakarrera, bideratzen dira eskualde-ospitaleetatik edo beraien etxeetatik. Lehen artatzea egiten duten medikuek (larrialdietan eta barne-medikuntzan) intentsibistei berri ematen diete, eta horiek ZIUan ospitaleratzea erabakitzen dute, proba osagarriei (erradiodiagnostikoa, ekokardiografia, larrialdietako laborategia) eta oinarrizko bizi-egoerari (onkologia, hematologia eta barne-medikuntza) erreparatuz. Behin ZIUan, estrategia terapeutiko egokiena aukeratzen dute intentsibistek, kardiologo interbentzionistek eta bihotzeko kirurgialariek elkarlanean (zenbaitetan biriketako birperfusioprimarioa, arrisku/onura-ren arabera) - GiTEP Kodea.

\section{BTE Kodearen aktibazioa eta jarduera-protokoloa}

Arrisku altuko (AA) eta arrisku ertain-altuko (AEA) BTEetan aktibatzen da BTEKodea, Europako Kardiologia Elkartearen 2014ko Gidako irizpideei jarraiki $\left(\right.$ ESC-2014) ${ }^{(7)}, 7$ egun arterainoko klinikarekin betiere.

\section{GITEP: BTE LARRIETARAKO JARDUERA-PROTOKOLOA GIPUZKOAN}

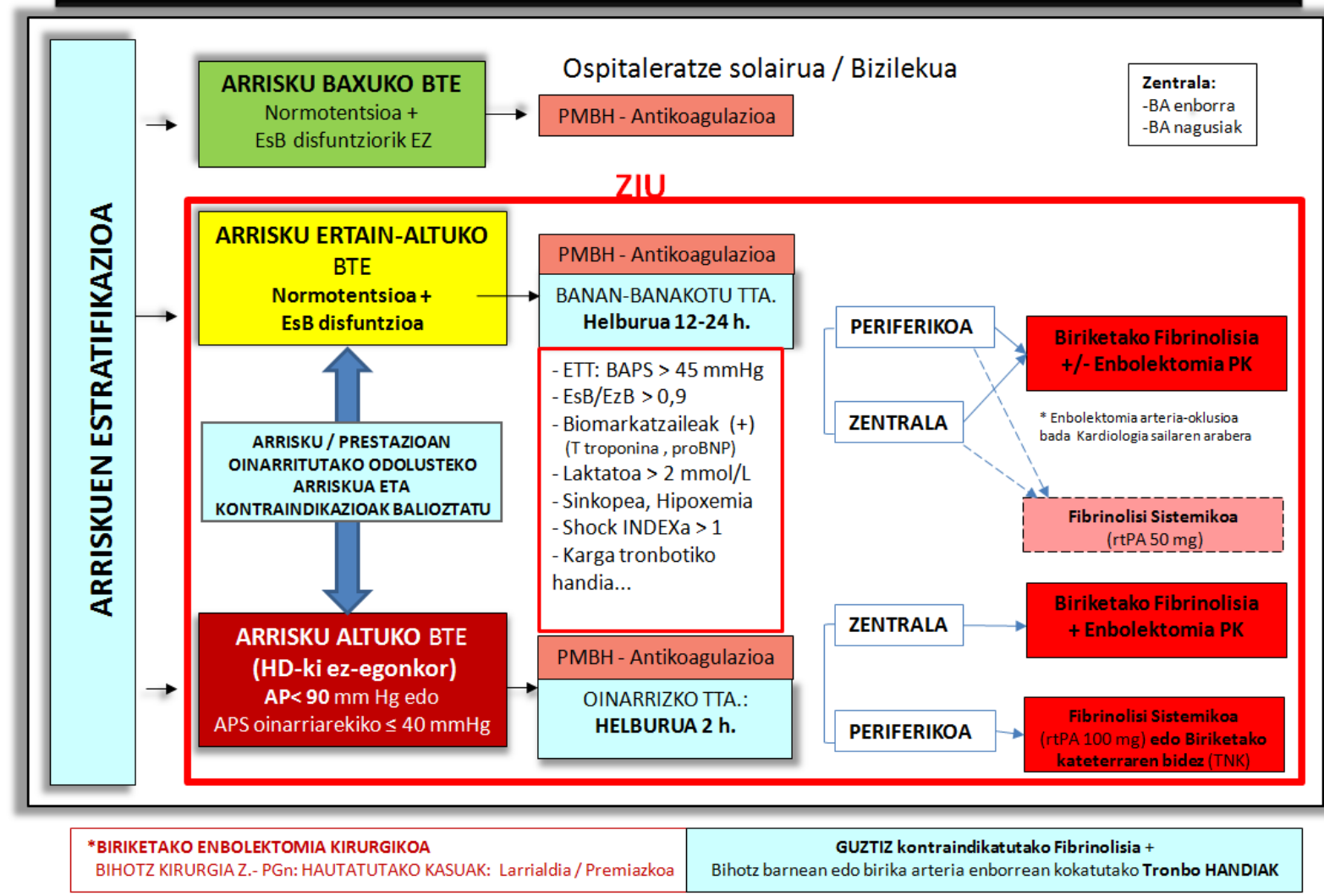

2. irudia. GiTEP: BTE larrietarako jarduera-protokoloa Gipuzkoan. Siglak: TTE: ekokardiografia transtorazikoa. BAPS: birika-arteriako presio sistolikoa. ZIU: zainketa intentsiboen unitatea. PMBH: pisu molekular baxuko heparina. EzB: ezkerreko bentrikulua. EsB: eskuineko bentrikulua.

Pisu molekular txikiko heparina (PMBH) bidezko antikoagulazioarekin batera, gure tratamenduprotokoloan beste hiru terapia ere jasotzen dira: kateter bidez gidatutako terapia farmakoinbasiboa (K-TFI), fibrinolisi sistemikoa (FS) eta gorputzez kanpoko zirkulazio bidez lagunduriko biriketako enbolektomia (E-GKZ) (2. irudia). 
Ezegonkortasun hemodinamikoa duten pazienteez gain, eta betiere hemorragia-arriskua kontuan hartuz (CRUSADE eskalan $\leq 40$ puntuko balioekin), birperfusio primarioa egingo zaie honako ezaugarriak betetzen dituzten pazienteei: Pulmonary Embolism Severity Index ${ }^{(8)}$ PESI $\geq 3$ edo PESI sinplifikatua ${ }^{(9)} \geq 1$, eskuineko bentrikuluaren (EsB) disfuntzio larria (EsB/EzB $>0,9$ ), biomarkagailuen igoera (T-troponina eta proBNP) eta birika-arteriako presio sistolikoa (BAPS) $\geq 40-45 \mathrm{mmHg}$. Pronostiko okerragoarekin erlazionaturiko beste markagailu batzuk ere ebaluatzen dirabirperfusio primarioaren alde egiteko: plasmako laktatoa $>2 \mathrm{mmol} / \mathrm{L}^{(10,11)}$, Shock Index $>1^{(12)}$, arnas gutxiegitasun akutua (SatO2 $<90 \%$ oinarrizko arnas lan areagotuarekin) eta karga tronbotiko altua ${ }^{(13)}$.

Ospitaleko prozesu osoa aztertzeaz gain, pneumologiako kanpo-kontsulten (KK) jarraipena egiten da, gutxienez lehen 6 hilabeteetan. Altarako planifikatuak geratzen dira etorkizunean egin beharreko froga osagarriak (ETT, biriketako angio-TK eta errutinazko analisia D dimeroarekin) eta hematologiako kanpo-kontsultetarako hitzordua, behar balitz tronbofilien ikerketa egiteko. Erregistratuak geratzen dira gainera, baleude, berrospitaleratzeko beharra, beste prozedura batzuk egiteko beharra edota lehen gertakariarekin erlazionaturiko arazoak.

Terapia guztiak DUOan egiten dira (osasun-sare publikoko erreferentzia-zentroa BTEaren tratamendurako), bihotzeko kirurgia izan ezik. Hori Policlínica Gipuzkoa (PG) ospitalean egiten da, sare publikoarekin itunduta baitago. BTE larria eta osasun-aseguru pribatuak dituzten zenbait paziente hasieratik PGn artatzen dira, eta ondorengo jarraipena GiTEP protokoloaren arabera egiten zaie. Prozesuen informazioa era koordinatuan jasotzen da aipatutako bi osasun-zentroetako ZIUetan.

\section{Aldagaiak}

Askeak: Epidemiologikoak eta Administratiboak ospitaleratzean, Aurrekari Pertsonalak, Tratamendu aurreko Kliniko-Analitikoak, Tratamendu aurreko Proba Osagarriak, Arrisku Eskalak, Tratamenduarekin erlazionatuak, Tratamendu osteko Kliniko-Analitikoak eta Ospitaletiko Altaren ondorengo Jarraipena. Menpekoak: Ospitalekoak eta Jarraipena (material gehigarrian deskribatzen da: A-B atalak).

\section{Analisi estatistikoa}

Analisi estatistikoak SPSS Statistics 20.0 (Statistical Package for the Social Sciences) Windowserako programarekin egin ziren. IBM ${ }^{\circ}, 2010$.

Aldagai kualitatiboak zenbaki zein proportzio absolutu edo erlatiboetan adierazten dira. Aldagai kuantitatiboak batezbesteko eta desbideratze estandar moduan adierazten dira, beharrezkoa denean mediana eta koartil arteko tarte (KAT) moduan adieraziz ${ }^{(14)}$.

Proportzioen arteko ezberdintasunak $\chi^{2}$ metodoarekin aztertu ziren, edo Fisherren test zehatzarekin hala behar izan zenean. Kategoria anitzeko aldagai kualitatiboen kasuan agregazio-prozesu bat egin zen, ebidentzia kliniko edo bibliografiko arrazoituekin betiere [14], ondoren $2 \times 2$ tauletan arriskuneurriak kalkulatzeko. Joerak ziurtatzeko erregresio-analisia erabili zen.

\section{Alderdi etikoak}

Ikerketa honek ikerketa klinikoetarako ospitaleko eta eskualdeko etika-batzordearen oniritzia izan zuen Gipuzkoan.

Legediak ezarritako ikerkuntzarako arau etiko eta eskakizun guztiak bete ziren, Helsinkiko Adierazpenean jasotako ikerkuntzarako printzipio etikoez gain.

Edozein terapia jaso edo/eta ikerketan sartuak izan baino lehen, pazienteek (edo beraien legeordezkariek) prozeduren inguruko informazio osoa jaso zuten, bai eta baimen informatua sinatu ere. Ikerketak iraun zuen bitartean ZIUan BTEagatik ospitaleratutako paziente guztiak sartu ziren ikerketan. 


\section{Interes-gatazkak}

Ikerketan parte hartu zuten ikertzaileek ez zuten inongo interes-gatazkarik adierazi.

\section{Emaitzak}

Ikerketak iraun zuen 5 urteetan 178 paziente ospitaleratu ziren ZIUan BTEaz diagnostikatuta. Ingresu/urte indizea progresiboki handitu zen urtetik urtera GiTEP martxan jarri ondoren, 3. irudian ikus daitekeenez.

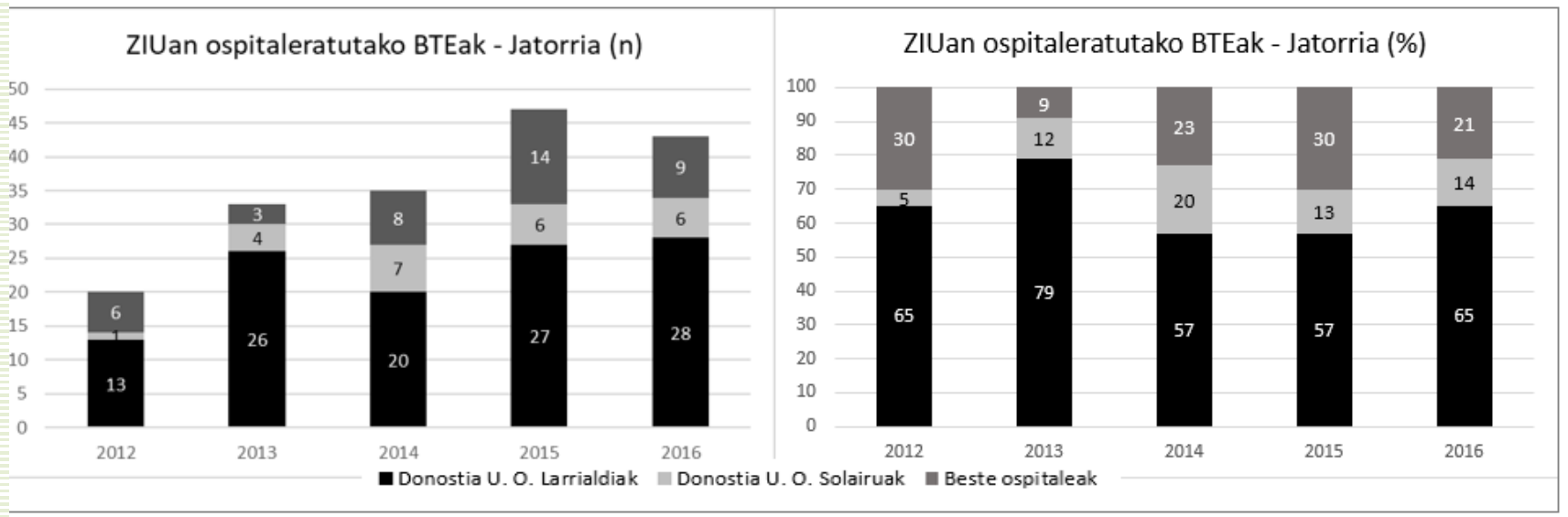

3. irudia. ZIUn ospitaleratutako BTE kasu kopurua, haien jatorri/urte indizea eta haren ehunekoa. Sigla: Donostia UO: Donostiako Unibertsitate Ospitalea.

Jatorriaren ehunekoetan ez zen aldaketa adierazgarririk ikusi. Ingresu/urte indizearen batezbestekoa 35 kasu/urtekoa izan zen, baina azken bi urteetan 45 kasu/urtera igo zen.

\section{Pazienteen ezaugarriak}

Batez besteko adina 62,5 urtekoa izan zen (KAT: 57,0-76,8), 21 eta 90 urte arteko tartearekin. \% 50,6 gizonezkoak izan ziren. 4. irudiak adinaren araberako banaketa adierazten du, igoera ia esponentzialarekin 20 urtetik 70 urtera bitartean.

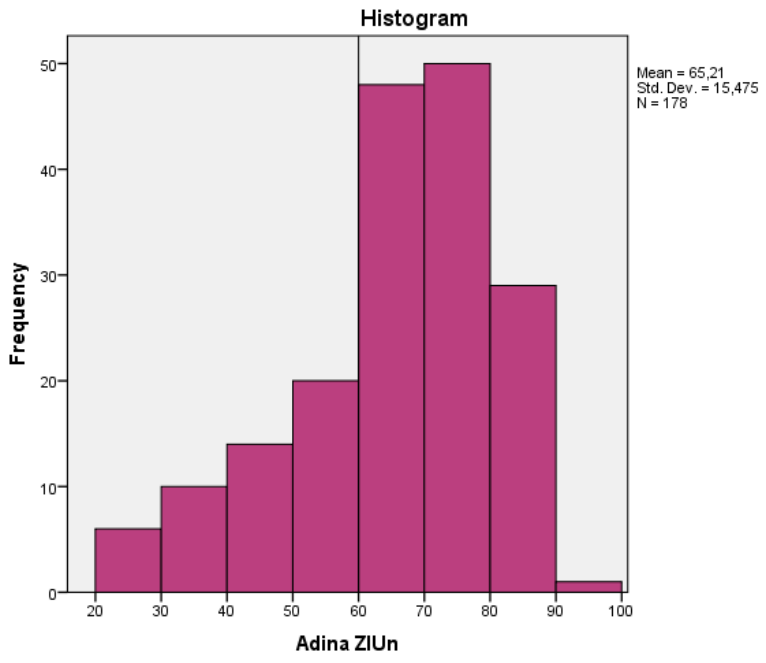

4. irudia. ZIUn ospitaleratutako BTE kasu kopurua eta haien banaketa adin-hamarkaden arabera.

1. taulak pazienteen ezaugarriak jasotzen ditu, hasierako sintomei, ospitaleratze-uneko larritasunzeinuei, aurrekariei eta zainetako gaixotasun tronboenbolikoa (ZGT) izateko arrisku-faktoreei dagokienez. 
1. Taula. Ezaugarri klinikoak, larritasun-zeinuak eta ospitaleratze-uneko aurrekariak.

\begin{tabular}{|c|c|c|c|}
\hline Egunak sintomekin & $\begin{array}{l}\text { Ospitaleratze aurrekoak (mediana } \\
\text { /KAT) }\end{array}$ & 1 & $(0-3)$ KAT \\
\hline \multirow[t]{3}{*}{ Disnea } & Bai & 156 & 87,6 \\
\hline & Bat-batekoa & 31 & 17,4 \\
\hline & Hemoptisiarekin & 3 & 1,7 \\
\hline \multirow[t]{2}{*}{ Bularreko mina } & Bai & 51 & 28,7 \\
\hline & Hemoptisiarekin & 2 & 1,1 \\
\hline \multirow{3}{*}{$\begin{array}{l}\text { Behe gorputz-adarretako } \\
\text { klinika }\end{array}$} & Bai & 56 & 31,5 \\
\hline & Mina & 29 & 16,3 \\
\hline & Edema & 27 & 15,2 \\
\hline \multirow[t]{2}{*}{ Sinkopea } & Sinkopea / errepikakorra & $39 / 8$ & $21,9 / 4,5$ \\
\hline & Presinkopea & 23 & 12,9 \\
\hline \multicolumn{2}{|c|}{ Ospitaleratze-uneko larritasun-zeinuak } & Kop. & $\%$ \\
\hline BBE & Bihotz-geldialdia & 9 & 5,1 \\
\hline Shock Index >1 & $\mathrm{BM}$ (t.m.) / AP (mmHg) & 40 & 22,5 \\
\hline Shock & Bai & 36 & 20,2 \\
\hline SatO2<\% 90 & $\begin{array}{l}\text { Arteriako Oxigeno Asetasuna (\%) } \\
<\% 90\end{array}$ & 52 & 29,2 \\
\hline \multirow[t]{2}{*}{ Oxigeno terapeutikoa } & Bai & 131 & 73,6 \\
\hline & $\begin{array}{l}\text { Intubatuak aireztapen } \\
\text { mekanikoarekin }\end{array}$ & 10 & 5,6 \\
\hline \multicolumn{2}{|c|}{ Aurrekariak eta zainetako gaixotasun tronboenbolikoa } & Kop. & $\%$ \\
\hline \multirow[t]{2}{*}{ Ohiko tratamendua } & Antiagregazioa & 36 & 20,2 \\
\hline & Antikoagulazioa & 4 & 2,2 \\
\hline \multirow[t]{3}{*}{ Aurretiko ZGT } & Aurretiko SZTa & 28 & 15,7 \\
\hline & Aurretiko BTEa & 15 & 8,4 \\
\hline & BTEarenfamilia-aurrekariak & 6 & 3,4 \\
\hline \multirow{3}{*}{$\begin{array}{l}\text { Sendagaiekin erlazionaturiko } \\
\text { aurretiko ZGTa }\end{array}$} & Ahozko antisorgailua & 4 & 2,2 \\
\hline & Kimioterapia & 1 & 0,6 \\
\hline & $\begin{array}{l}\text { Antigorputz monoklonalak } \\
\text { (Rituximab) }\end{array}$ & 2 & 1,1 \\
\hline Gaixotasun onkologiko & Aktiboa & 25 & 14,0 \\
\hline Ezaguna & Ez-aktiboa & 6 & 3,4 \\
\hline Aurretiko immobilizazioa & & 48 & 27,0 \\
\hline \multirow[t]{3}{*}{ Aurretiko ebakuntza } & Ebakuntza egindakoak & 23 & 12,9 \\
\hline & Ebakuntza inguruko profilaxia & & \\
\hline & Enoxaparinarekin & 18 & 78,3 \\
\hline
\end{tabular}

Aldagai jarraituak: mediana eta koartilen arteko tartea (KAT). Aldagai diskretuak: ZIUanospitaleratutako kasu guztien kopurua (Kop.) eta portzentajea (\%). BBE: batez besteko egonaldia. Shock Index: BM (bihotz-maiztasuna, t.m.)/AP (arteria-presioa, mmHg). ZGT: zainetako gaixotasun tronboenbolikoa. SZT: sakoneko zain-tronbosia. BTE: biriketako tronboenbolismoa.

Ikus daitekeenez, disnea izan zen hasierako sintoma nagusia. Zainetako gaixotasun tronboenbolikoaren aurrekariak eta gaixotasun onkologikoa nabariak izan ziren.

\section{BTEaren ezaugarriak}

ESC-2014ren irizpideei jarraiki, ZIUan ospitaleratutako kasu gehienak arrisku ertain-altukoak (AEA) izan ziren (\% 52,8), arrisku altukoez (AA) jarraituta (\% 20,2). Soilik kasu bakar bat ezin izan zen estratifikatu. 
2. Taula. Larritasun-zeinuak eta ZIUan ospitaleratutako BTEen banaketa

Larritasun-markatzaileak

BTEaren diagnostiko estratifikatua
(ESC 2014 Eredua)
PESI

PulmonaryEmbolismSeveritylndex

$\begin{array}{lcc} & \text { Kop. } & \% \\ \text { Estratifikaezina } & 1 & 0,6 \\ \text { Arrisku baxua (AB) } & 21 & 11,8 \\ \text { Arrisku ertain-baxua (AEB) } & 26 & 14,6 \\ \text { Arrisku ertain-altua (AEA) } & 94 & 52,8\end{array}$

Arrisku altua (AA) $36 \quad 20,2$

I. Klasea: arrisku oso baxua $21 \quad 11,8$

II. Klasea: arrisku baxua $\quad 34 \quad 19,1$

III. Klasea: arrisku ertaina $\quad 46 \quad 25,8$

IV. Klasea: arrisku altua $\quad 34 \quad 19,1$

V. Klasea: arrisku oso altua $\quad 43 \quad 24,2$

$\begin{array}{lccc}\text { Eskuinekobentrikuluaren (EsB) } & \text { Bai } & 145 & \mathbf{8 1 , 5} \\ \text { disfuntzioa } & \text { Ezezaguna } & 2 & 1,1 \\ & \text { VD/VI } \geq 0,9 & 102 & 57,3 \\ & \text { Ezezaguna } & 37 & 20,8 \\ \text { TAPSEa ospitaleratzean } & <15 \text { mmHg } & 26 & 14,6 \\ & \text { Hutsegindakoa } & 62 & 34,8 \\ \text { BAPSa ospitaleratzean (ETT) } & \text { Ezezaguna } & 30 & 16,9 \\ & \mathbf{4 5} \text { mmHg } & 89 & 50,0 \\ & \text { Hutsegindakoa } & 20 & 11,2 \\ \text { BAPSa ospitaleratzean } & \text { Ezezaguna } & 26 & 14,6 \\ \text { (Birika Arteriografia) } & \mathbf{4 5} \text { mmHg } & 49 & \mathbf{2 7 , 5} \\ & \text { Egindako birika- } & 65 & 36,5\end{array}$

\begin{tabular}{llcc} 
Troponina $(+)$ & Bai & 139 & 78,1 \\
(Beheko muga $>$ T o I) & Ezezaguna & 5 & 2,8 \\
\hline Pro-BNP $(+)$ & Bai & 138 & 77,5 \\
$(\geq 500 \mathbf{~ p g} / \mathbf{m L})$ & Ezezaguna & 4 & 2,2 \\
Kokapena & Zentrala & 142 & 79,8 \\
& Bihotz barrukoa & 1 & 0,67 \\
& Birika-arteriaren & 12 & 6,7 \\
& enborrekoa & 129 & 72,5 \\
& Birika-arteria & & \\
& nagusietakoa & & \\
& Periferikoa & 36 & 20,2 \\
& Lobarrra & 31 & 17,4 \\
& Segmentarioa & 5 & 2,8 \\
SZTa ospitaleratzean & Guztira & 113 & 63,5 \\
& Enboliarako arrisku altua & 24 & 13,5 \\
& Ezezaguna & 12 & 6,7
\end{tabular}

Aldagai diskretuak: ZIUan ospitaleratutako kasu guztien kopurua (Kop.) eta portzentajea (\%). EsB/EzB erlazioa ETT edo TK bidez. Birika-arteriako presio sistolikoa (BAPS), sakoneko zaintronbosia (SZT), tronboak badaude zain femoralaren 2/3 proximaletan edo/eta safena zainaren sifoian.

Pazienteen lehen ebaluazioaren ondoren, GiTEP Kodea aktibatzen da arrisku handienekoetan (AA eta AEA) erantzun azkarreko diziplina anitzeko taldearen bidez, baldin eta esfortzu terapeutikoaren egokitzapena egitea erabakitzen ez bada. Talde hori ZIUko, kardiologia interbentzionistako eta bihotzeko kirurgiako guardiako medikuek osatzen dute, eta beraiek erabakitzen dute zein izango den kasu bakoitzean erabiliko den estrategia terapeutikoa. 2. taulan deskribatzen dira larritasun-zeinuak etahaien banaketa arrisku-taldeetan. 
Antikoagulazioa izan zen ikerketa honetako pazienteekin gehien erabilitako tratamendua (ikus 5. irudia). 4 kasutan tratamendurik ez aplikatzea erabaki zen haien erreferentziazko medikuekin adostuta, paziente horiek goiztiarki ospitaleratze-solairura pasa zirelarik.

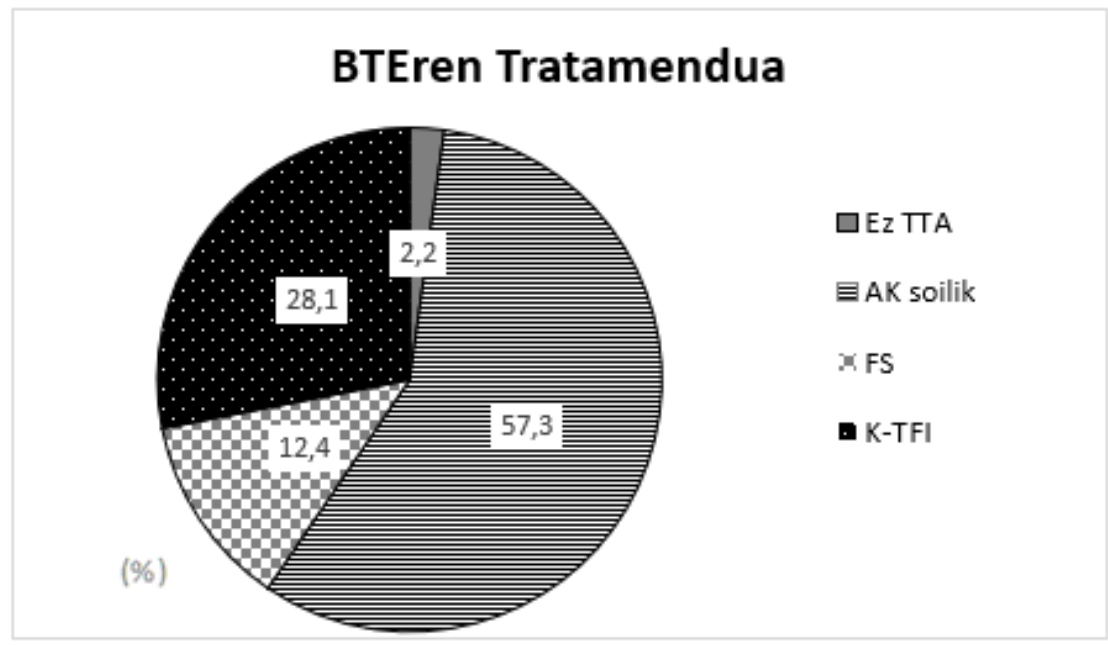

5. irudia. ZIUan ospitaleraturako BTEetan egindako tratamenduak (portzentajeak). Siglak: Ez TTA: tratatu gabeak. Siglak: AK: Antikoagulazioa soilik. FS: Fibrinolisi sistemikoa. K-TFI: Kateter bidez gidatutako terapia farmakoinbasiboa.

6. irudian ikus daitekeenez, antikoagulazio soilarekin trataturiko pazienteen proportzioa urte batetik bestera aldakorra izan bazen ere, aldakortasuna ez zen estatistikoki esanguratsua izan ( $p$ trendEE). Fibrinolisi sistemikoa gero eta gutxiago erabili zen, kateter bidez gidatutako TFla bihurtu zelarik aukera egokiena birperfusioprimariorako ( $p$ trend $<0,05$ bietan).

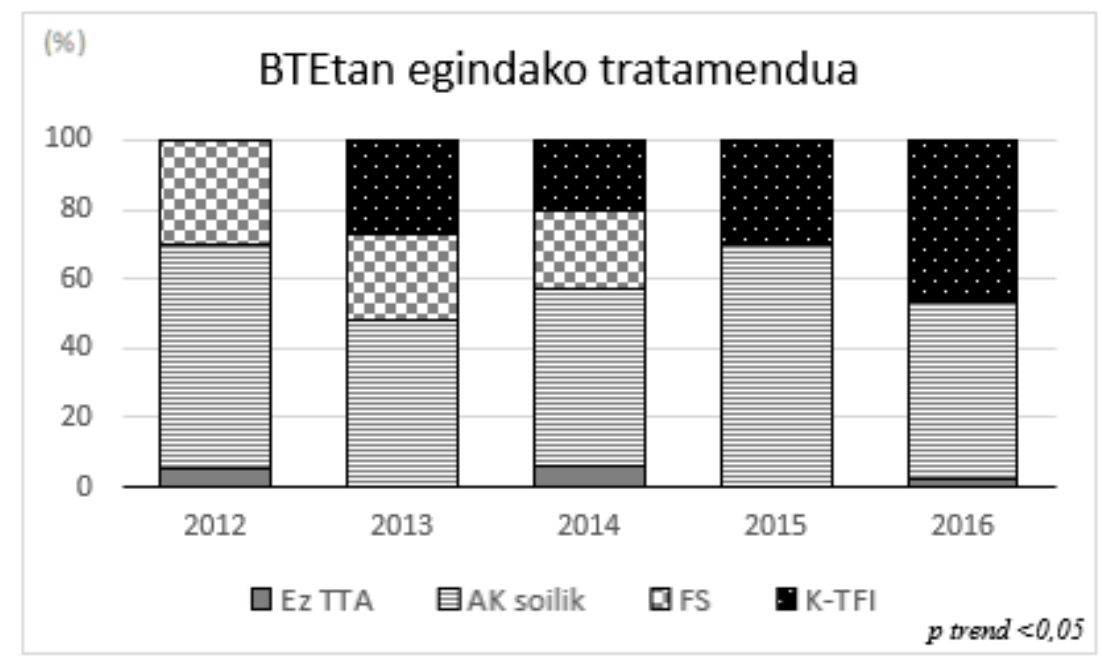

6. irudia. ZIUan ospitaleratutako BTEei aplikatutako tratamenduak (portzentajeak), urteka banatuta. Siglak: AK: Antikoagulazioa soilik. FS: Fibrinolisi sistemikoa. K-TFI: Kateter bidez gidatutako terapia farmakoinbasiboa.

- GiTEP Kodearen aktibazioa:

178 ospitaleratzeetatik 124tan aktibatu zen GiTEP Kodea: arrisku altuko 36tik 35etan eta arrisku ertain-altuko 94tik 89tan, antikoagulaziodun birperfusio primarioa egin zelarik $72 \tan$ (\% 58,1). Premiazko birperfusio honetarako gehien erabili zen teknika kateter bidez gidatutako TFla izan zen, fibrinolisi sistemikoakarga tronbotikoa batez ere periferikoa zen kasuetarako soilik utziz. 
Ez zen aktibatu kodea arrisku altuko paziente baten kasuan eta arrisku ertain-altuko beste bosten kasuan, erreferentziazko medikuekin batera esfortzu terapeutikoaren egokitzapena egitea erabaki zelako. Arrisku txikieneko taldeetako (AEB eta $A B$ ) pazienteekin ere ez zen GiTEP Koderik aktibatu, eta antikoagulazio soilarekin tratatu ziren.

7. irudian deskribatzen dira egindako tratamenduak arrisku-taldeen arabera banatuta. Birperfusio primarioa AAkoBTEen \% 66,7an eta AEAkoen \% 51n egin zen.

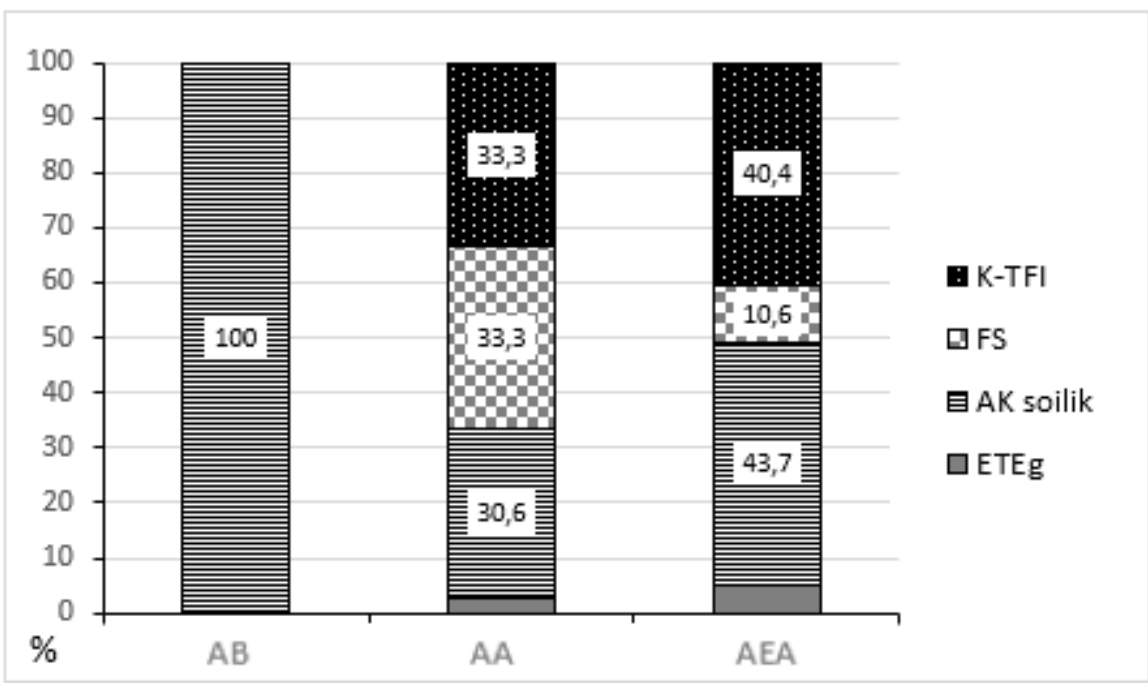

7. irudia. ZIUan ospitaleratutako BTEeiegindako tratamenduak (portzentajeak) arrisku-taldeen arabera sailkatuta. Siglak: AA: arrisku altua, AEA: arrisku ertain-altua, AB: arrisku baxua (arrisku baxua eta arrisku ertain-baxua barne hartuz). ETEg: esfortzu terapeutikoaren egokitzapena. AK: antikoagulazioa soilik. FS: Fibrinolisisistemikoa. K-TFI: kateter bidez gidatutako terapia farmakoinbasiboa.

- Beheko kaba zaineko iragazkiak (BKZ):

Aldi bereko sakoneko zain-tronbosiaren prebalentzia altua izan zen (\% 63), \% 10 baino gehiago (24 kasu) beheko gorputz-adarretako arrisku altuko tronbosiak izan zirelarik (zain proximaletan kokatuak mobilizaziorako arrisku altuarekin eta/edo antikoagulazio-maila egokiak lortzeko zailtasuna zutenak). Bost kasutan soilik ezarri zen beheko kaba zaineko iragazkia (\% 20,8), guztiak behin-behinekoak.

\section{Eboluzioa: konplikazioak eta hilkortasuna}

- Konplikazio hemorragikoak (Bleeding Academic Research Consortium-en dokumentu bateratuaren arabera - BARC $\left.^{(15)}\right)$ : pazienteen \% 6,7kizan zuen konplikazio hemorragikoren bat, gehienak 1 . motakoak edo arinak izaki (12 kasutik 10etan), eremu bigunetako edo zulatze-eremuetako hemorragia arinekin lotuak. Beste biak 3. motako konplikazio hemorragiko modura sailkatu ziren, 3 hematie-kontzentraturen transfusioa behar izan zutelako, nahiz eta batek berak ere ez zuen biziarriskurik izan.

-Giltzurrun-gutxiegitasun akutua (GGA) - Acute Kidney Injury (AKI) 2. edo 3. aldian ${ }^{(16)}$ : \% 8,4an jazo zen, nahiz eta batek berak ere ez zuen giltzurruneko ordezkapen-terapiarik behar izan.

-Arnas gutxiegitasun larria: intubatutako 10 pazienteetatik batek berak ere ez zuen aireztapen mekanikorik (AM) denbora luzean behar izan (7 egun baino gehiago), eta ez zen AMari loturiko pneumonia-kasurik antzeman.

ZIUko batez besteko egonaldia (BBE) 3,7 $\pm 3,5$ egunekoa izan zen, 3 eguneko medianarekin (KAT 2-4), eta ospitaleko egonaldia, berriz,11,1 \pm 9,0 egunekoa, 9 eguneko medianarekin (KAT 7-12). Arriskuaren estratifikazioaren arabera aztertuta (ESC 2014 eredua), ez zen ezberdintasun esanguratsurik antzeman, nahiz eta BTEaren larritasunari loturiko ospitaleratze luzeagoaren joera sumatu ( $p$ trend $E E)$. 
Ospitaleko hilkortasuna \% 6,2koa izan zen. Hamaika heriotzatik hiru hemodinamika-gelan geratu ziren (horietatik bi bihotz-biriketako geldialdian iritsi ziren bertara), eta beste zortziak ZIUan, gehienak bihotz-biriketako geldialdiagatik (sei disoziazio elektromekanikoagatik, bat organo anitzeko disfuntzioagatik eta beste bat biriketako gaixotasun buxatzaile kroniko aurreratuari loturiko arnas gutxiegitasun global larriagatik).

Hamaika hildakoetatik hamar arrisku altuko taldekoak ziren (\% 91), bestea arrisku ertainbaxukotaldekoa zelarik, zeinari esfortzu terapeutikoaren egokitzapena egin zitzaion GiTEP Kodea aktibatu gabe.

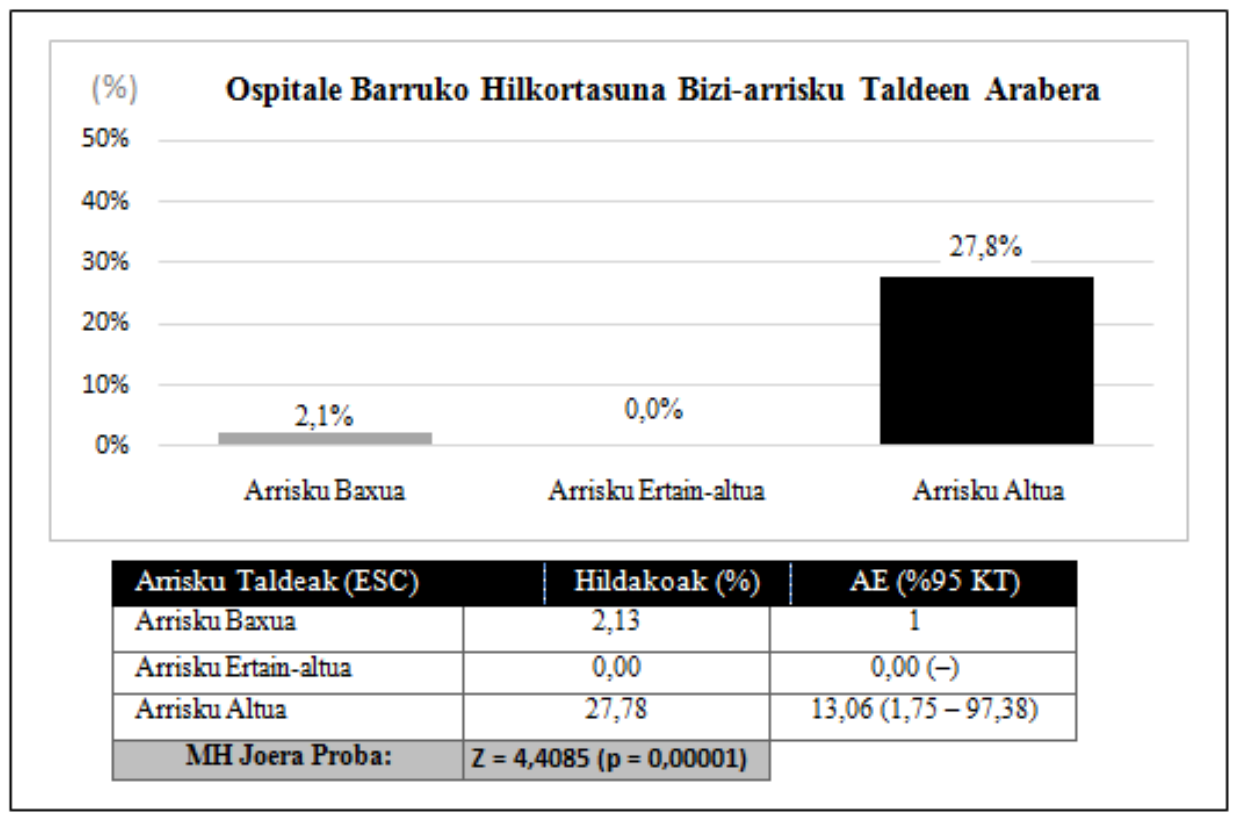

8. irudian BTEaren larritasunaren araberako hilkortasuna erakusten da ( $P$ trend 0,001$)$, arrisku baxukoak eta ertain-baxukoak arrisku baxuko taldean bildu zirelarik. Siglak: ESC: European Society of

Cardiology. AE: arrisku erlatiboa. \% 95 KT: \% 95eko konfiantza-tartea. MH: Mantel-Haenszel.

Gutxienez 6 hilabeteko jarraipena egin zen pazienteen \% 97an, BTEaren berragertzerik antzeman gabe, nahiz eta 6 sakoneko zain-tronbosi kasu (\% 3,5) hauteman, antikoagulazioa amaitu ondoren agertuak guztiak. New York Heart Association-en (NYHA) sailkapenari jarraiki, \% 75,3 disnearik gabe zegoen, \% 21,6 II gradu funtzionalean (GF) eta \% 1,2 III-IV GFan. EsBaren disfuntzio arina antzeman zen ETT bidez kasuen \% 8,6an, eta soilik \% 4,3k zuen BAPS $>40 \mathrm{mmHg}$. Jarraipen-aldi honetan paziente bat hil zen gaixotasun onkologikoagatik eta hilkortasuna $\%$ 6,7an finkatuzen.

\section{Eztabaida eta ondorioak}

Gipuzkoan biriketako tronboenbolismoari erantzuteko diziplina anitzeko talde baten jarduera aurkezten du artikulu honek. Lurralde honen ezaugarri soziosanitarioek ahalbidetu zuten zIUan ospitaleratutako BTEdun paziente guztien datuak jasotzea, laginari adierazgarritasun handia emanez, eta balioespen irmoak egitea ahalbidetuz jarduera-mailari, diagnostikoari, terapeutikari eta jarraipenari buruz. Gipuzkoako osasun-eremuak 800.000 biztanleko populazioa du, mendebaldeko gainerako herrialdeetakoen moduan zahartzen ari dena, eta, batez beste, urteko 1.200 ZGT kasu sintomatikoko tasa egokitzen zaio. ZGThorien herenak BTE bat gara lezakeela suposatzen bada, urteko 300 BTE kasu izango lirateke, eta, beraz, ondoriozta liteke ZIUetara \% 10 iristen dela batez beste.

Ikerketa hau 5 urteko epean garatu zen (2012-2016), BTE larridun pazienteen ezaugarriak deskribatuz, bai eta horiek artatzeko diziplina anitzeko taldeak sortu ondoren txertatutako aldaketak azalduz. Erreferentzia garrantzitsua izan zen Jiménezet al.-ek argitaratutako lana ${ }^{(17)}, 2001$ eta 2013 urteen artean BTE akutudun pazienteen kudeaketaren joerari eta emaitzei buruzkoa, RIETE 
erregistroaren bidez egina (erregistro prospektiboa, multizentrikoa eta internazionala), nahiz eta lan horrek ez barne hartu ZIUan ospitaleratutako pazienteak.

Gure seriean, disnea izan zen BTEdun pazienteak larrialdietara joateko arrazoi nagusia, normalean ez bat-batekoa eta nagusiki 24-48 orduko eboluziokoa. Kasuen herenean bularreko minarekin, beheko gorputz-adarretako klinikarekin edo sinkope/presinkopeekin batera agertu zen, konbinazio hori diagnostikorako susmo altukoa delarik. Ospitaleratze-uneko larritasun-zeinuei dagokienez, \% 5ek batbateko heriotzarekin egin zuen debuta eta bostetik bat shock egoeran iritsi ziren ospitalera. \% 30 inguru <\%90eko SatO2arekin ospitaleratu zen, baina soilik \% 5ek behar izan zuen intubazioa, gehienetan bihotz-biriketako bizkortze baten testuinguruan. Orokorrean, karga tronbotikoa altua izan zen, kasuen \% 80an tronbo zentralak agertu zirelarik, bai birika-arteria nagusietan baita bihotz barruan ere, kasuen erdian baino gehiagotan sakoneko zain-tronbosiarekin batera. Sintoma eta zeinu horiek normalki argitaratutakoak ${ }^{(18)}$ baino portzentaje altuagoetan azaltzea, ziur aski, ZIUan ospitaleratutako pazienteak soilik kontuan hartzearekin lotuta dago, PERT-MGHan bezala ${ }^{(19)}$.

Deigarria da kasuen \% 24,1ek ZGT baten aurrekariak zituela, eta \% 17,4k aurrekari onkologikoak, nahiz eta RIETE seriean baino portzentaje baxuagoan, aurretik azaldutakoagatik ziur asko. Arriskufaktoreen artean nabarmentzekoa da BTEaren aurreko egunetan immobilizatuta egondako pazienteen kopurua (\% 27), ebakuntza baten aurrekaria zutenen bikoitza.

ZGTa epe ertain-luzerako gaixotasun baten moduan ulertu beharko genuke, estrategia diagnostikoak eta terapeutikoak BTE baten moduko gertaera akutu batetik bizirik irteteko nahiz bizi-kalitatea okertzen duten ${ }^{(20)}$ konplikazio eta sintoma kronikoak ekiditeko erabiliz ${ }^{(21,22)}$. GiTEP Kodea helburu horiekin sortu zen, eta 2012an martxan jarriz geroztik, gero eta arrisku ertain-altuko paziente gehiago ospitaleratu dira Gipuzkoako ZIUetan, eta horietako askori (\% 51) birperfusio primariorako terapiak aplikatu zaizkie. Arrisku altukoen ospitaleratzea ere arinki areagotu da, \% 70 premiaz birperfunditu direlarik. Beste ospitaleetan ere antzeko emaitzak errepikatzen dira diziplina anitzeko taldeak (PERTak) sortu ondoren ${ }^{(19)}$. Horren zergatia, agian, estratifikazio hobeago batean eta GiTEP Kodearen aktibazioan datza, birika-arterian kateter bidez gidatutako TFla erabiltzen hastearekin batera. Teknika hori bilakatu da tratamendu erabiliena arrisku altukoen artean, arrakasta-portzentaje altuarekin eta konplikazio hemorragiko larririk gabe. 2015ean argitaratutako PERFECT ${ }^{(23)}$ eta SEATTLE II $^{(24)}$ ikerketa multizentrikoek guk hartutako bidea indartu zuten, zeintzuetan lehen emaitza onak izan zituzten egonkortze hemodinamikoari, birika-arteriako presioa gutxitzeari eta biziraupenari zegokienez, konplikazio hemorragia kointrakranealik antzeman gabe. Orduz geroztik asko ugaritu dira gai honi buruzko berrikuspenak, metaanalisiak eta ikerketa berriak, zeintzuek hemorragia-arrisku altuko BTE akutu larrien ${ }^{(25-36)}$ tratamendurako kateter bidez gidatutako teknika berrien eraginkortasuna egiaztatzen jarraitzen duten, bai eta tronboen xurgaketarako gailu eraginkorragoenak ere, FlowTriever System (Inari) ${ }^{\circledR(33)}$ edo Indigo System (Penumbra) ${ }^{\circledast{ }^{(25)}}$ bezalakoak esaterako.

\section{- GiTEP Kodearen aktibazioa:}

Arrisku altuko pazienteetan automatikoki aktibatzen da GiTEP Kodea, erraz detekta baitaitezke kolapso hemodinamikoagatik edo/eta arnas zailtasun larriagatik, estrategia terapeutiko egokiena aukeratzen delarik, larritasunaren arabera hemorragia-arrisku handiagoak onartuz.

Arrisku ertaineko talde heterogeneoak zailtasun handiagoak mahaigaineratzen ditu, oraindik ez baitago paziente horien estratifikaziorako irizpide bateraturik, eta, beraz, ez baitago argi zeintzuk tratatu beharko liratekeen modu aktiboago batean, bai biziraupena hobetzeko zein epe luzerako ondorioak gutxitzeko.

ESC-2014 ereduak ez du eztabaida hau konpondu, bertan agertzen diren lau kategoriak nahasgarri samarrak baitira. Arrisku altuko pazienteak errazago bereizi beharko genituzke beste guztietatik. PEHITO ikerketaren ${ }^{(37)}$ egileek arrisku ertain-altukotzat hartzen dituzte EsBaren disfuntzioa eta Ttroponinaren igoera dituzten pazienteak, ezaugarri horiek seinala dezaketelarikarrisku baxukoengatiko ebaki-puntua. 
Gure taldeak, arrisku ertain-altukoak ZIUan ospitaleratzeaz gain, GiTEP Kodea aktibatu zuen horietako bakoitzarekin, birperfusio primariorako terapiaren arrisku/onura balioetsiz honako ezaugarriak betez gero:

1. Arrisku ertain-altua(ESC 2014 ereduaren arabera).

2. EsBaren disfuntzio larria (VD/VI erlazioa $\geq 0,9$ ).

3. BAPS $>40-45 \mathrm{mmHg}$ (edo EsBaren presio telediastolikoa $>40 \mathrm{mmHg}$ ).

Modu aktiboan tratatzearen alde egin zuten honako ezaugarriek ere:

- Shock Index $>1$ etalaktato igoera (>2 $\mathrm{mmol} / \mathrm{L}$ ), ezkutuko shock-egoera baten erakusle izan litezkeelako, eta, beraz, arrisku altuaren adierazle.

- Hipoxemiadun arnas gutxiegitasuna (SatO2<\% 90) eta arnas lanaren areagotzea.

Birperfusio primarioaren aukera atzera bota zenFSrako erabateko kontraindikazioak zeuden kasuetan (koagulopatia edo tronbopenia), CRUSADE $>40$ ko puntuazioa hartuz hemorragia-arrisku altuaren langatzat.

Zalantzazko kasuetan, erabakien algoritmoan tratamendu aktiboaren aldeko (K-TFI edo FS) puntutzat gehitu ziren karga tronbotiko altua izatea (tronbo zentral handiak eta beheko gorputz-adarretako tronboengatiko enbolia errepikakorren arriskua) edo errepikapenezko sinkopeak. Copeptinaren moduko adierazle berriak gehitzeko lanek aurrera diraute ${ }^{(38)}$.

FSa arrakastatsutzat jotzen da egonkortze hemodinamikoa eta biziraupena lortzen badira. Kateter bidez gidatutako K-TFlaren arrakasta-irizpideak ere hemodinamikoak eta biziraupenari dagozkionak dira batez ere, BAPSaren \% 20ko murrizpena ere helburutzat hartzen bada ere, tronboen erabateko desagerpenaren bila interbentzionismoa luzatzea ekidinez.

GiTEP Kodea martxan jartzearekin batera, pneumologiako zerbitzuaren esku geratu ziren ospitaleratze-solairuko egonaldia bai eta kanpo-kontsultetako jarraipena ere, zeina bizirik irtendako pazienteen \% 95ean bete ahal izan zen.

Jarraipen horri esker lortu zenGiTEP protokoloaren emaitza kliniko errealak sistematikoki aztertzea, bai epe motzekoak (hilkortasuna eta errekurrentzia), bai eta epe luzekoak ere (edozein arrazoirengatiko hilkortasuna, gradu funtzionala, birikako hipertentsio kroniko sekundarioa eta bizikalitatea).

Zentzuzkoa dirudi prozesu honetan kudeaketa ekonomikorako erremintak sortzeak eta txertatzeak, bai ospitaleko aldiko kostuen kontrolerako, bai eta jarraipenekoetarako, are gehiago postBTE sindromearen garrantzia egiaztatuz gero. Arriskuen arabera eta tratamendu moten arabera gastuak aztertzeak, eta pazienteko edo prozesuko gastuen ezagutzak, kudeaketa eraginkorrago bat egiten lagunduko luke ziur asko.

Ikerketaren muga moduan aipatzekoa da, jasotako datuen artean, ospitaleratzeko birika-arteriako presio sistolikoaren (BAPS) eta eraztun trikuspideoaren ibilbide-denboraren (TAPSE) neurketa akastun edo egin gabekoen proportzioa altua dela. Gainera, ez dugu ECMOarekin (gorputzez kanpoko mintz bidezko oxigenazioa) inolako esperientziarik, ez dugulako terapia horretarako sarbiderik gure ospitaleetan, nahiz eta haren erabilera justifikatuta legokeen zenbait kasutan ${ }^{(39,40)}$. Ez dugu, ezta ere, Gipuzkoako autopsietako daturik, BTEa bat-batean hildako zenbat pazienteren atzean legokeen jakiteko, ziur askoheriotza-kausa hau infraestimatu egiten baita ${ }^{(41)}$.

\section{Ondorioak}

Biriketako tronboenbolismo larriaren diziplina anitzeko artatzeak jokaera proaktiboago eta antolatuago bat ahalbidetu du paziente hauen tratamenduan, konplikazio hemorragiko larririk gabe eta espero baino hilkortasun baxuagoarekin. 
Beharrezkoa da, hala ere, ikerketa gehiago egitea arrisku ertain-altukopazienteetan FS edo TFI bidezko birperfusioprimarioaren indikazioei buruzko ebidentzia handiagoa lortzeko,bai eta horien eboluzioa ezagutzeko ospitaleko altaren ondorengo jarraipenean.

\section{Erreferentziak bibliografikoak}

[1] Provias T, Dudzinski DM, Jaff MR, Rosenfield K, Channick R, Baker J, Weinberg I, Donaldson C, Narayan R, Rassi AN, Kabrhel C. The Massachusetts General Hospital Pulmonary Embolism Response Team (MGH PERT): creation of a multidisciplinary program to improve care of patients with massive and submassive pulmonary embolism. Hosp Pract (1995). 2014;42:31-7. doi:10.3810/hp.2014.02.1089.

[2] Jaber WA, Fong PP, Weisz G, Lattouf O, Jenkins J, Rosenfield K, Rab T, Ramee S. Acute pulmonary embolism: with an emphasis on an interventional approach. J Am Coll Cardiol. 2016;67(8):9911002. doi:10.1016/j.jacc.2015.12.024.

[3] Dudzinski DM, Piazza G. Multidisciplinary pulmonary embolism response teams. Circulation. 2016;133:98-103. doi:10.1161/CIRCULATIONAHA.115.015086.

[4] Barnes G, Giri J, Courtney DM, Naydenov S, Wood T, Rosovsky R, Rosenfield K, Kabrhel C. Nuts and bolts of running a pulmonary embolism response team: results from an organizational survey of the National PERT ${ }^{\mathrm{TM}}$ Consortium members. Hosp Pract. 2017:1-5. doi:10.1080/21548331.2017.1309954.

[5] Rodriguez-lopez J, Channick R. The Pulmonary Embolism Response Team : what is the ideal model ? Semin Respir Crit Care Med. 2017;38:51-5. doi:http://dx.doi.org/ 10.1055/s-00361597561. ISSN 1069-3424.

[6] Kabrhel C. Achieving Multidisciplinary Collaboration for the Creation of a Pulmonary Embolism Response Team: Creating a "Team of Rivals." Semin Interv Radiol. 2017;34(1):16-24. doi:10.1055/s-0036-1597760.

[7] Konstantinides S V, Torbicki A, Agnelli G, Danchin N, Fitzmaurice D, Galiè N, Gibbs JS, Huisman MV, Humbert M, Kucher N, Lang I, Lankeit M, Lekakis J, Maack C, Mayer E, Meneveau N, Perrier A, Pruszczyk P, Rasmussen LH, Schindler TH, Svitil P, Vonk Noordegraaf A, Zamorano JL, Zompatori M; Task Force for the Diagnosis and Management of Acute Pulmonary Embolism of the European Society of Cardiology (ESC). 2014 ESC guidelines on the diagnosis and management of acute pulmonary embolism. Eur Heart J. 2014;35(43):3033-69, 3069a3069k.doi:10.1093/eurheartj/ehu283.Epub 2014 Aug 29. Erratum in: Eur Heart J. 2015 Oct 14;36(39):2666. Erratum in: Eur Heart J. 2015 Oct 14;36(39):2642.

[8] Aujesky D, Obrosky DS, Stone RA, Auble TE, Perrier A, Cornuz J, Roy PM, Fine MJ. Derivation and Validation of a Prognostic Model for Pulmonary Embolism. Am J Respir Crit Care Med. 2005;172(8):1041-6. doi:10.1164/rccm.200506-8620C.

[9] Jiménez D, Aujesky D, Moores L, Gómez V, Lobo JL, Uresandi F, Otero R, Monreal M, Muriel A, Yusen RD. Simplification of the pulmonary embolism severity index for prognostication in patients with acute symptomatic pulmonary embolism for the RIETE investigators. Arch Intern Med. 2010;170(15):1383-9. doi:10.1001/archinternmed.2010.199.

[10] Vanni S, Viviani G, Baioni M, Pepe G, Nazerian P, Socci F, Bartolucci M, Bartolini M, Grifoni S. Prognostic value of plasma lactate levels among patients with acute pulmonary embolism: The thrombo-embolism lactate outcome study. Ann Emerg Med. 2013;61(3):330-8. doi:10.1016/j.annemergmed.2012.10.022.

[11] Vanni S, Jiménez D, Nazerian P, Morello F, Parisi M, Daghini E, Pratesi M, López R, Bedate P, Lobo JL, Jara-Palomares L, Portillo AK, Grifoni S. Short-term clinical outcome of normotensive patients with acute PE and high plasma lactate. Thorax. 2015;70(4):333-8. 
doi:10.1136/thoraxjnl-2014-206300.

[12] Jaff MR, McMurtry MS, Archer SL, Cushman M, Goldenberg N, Goldhaber SZ, Jenkins JS, Kline JA, Michaels AD, Thistlethwaite P, Vedantham S, White RJ, Zierler BK; American Heart Association Council on Cardiopulmonary, Critical Care, Perioperative and Resuscitation; American Heart Association Council on Peripheral Vascular Disease; American Heart Association Council on Arteriosclerosis, Thrombosis and Vascular Biology. Management of Massive and Submassive Pulmonary Embolism, Iliofemoral Deep Vein Thrombosis, and Chronic Thromboembolic Pulmonary Hypertension: A Scientific Statement From the American Heart Association. Circulation. 2011;123(16):1788-830. doi:10.1161/CIR.0b013e318214914f.

[13] Tapson VF, Weinberg AS. Treatment, prognosis, and follow-up of acute pulmonary embolism in adults. 2020 [Eguneratuta:2020-11-09 ; Kontsulta: 2020-12-03]. Hemen: Uptodate [Internet]. Waltham (MA): c2020. [70 or.]. Eskuragarri:https://uptodate.com/.

[14] Doménech Massons JM, Granero R. Fundamentos de diseño y estadística. Descripción de datos cuantitativos. 11a ed. Barcelona: Signo; 2010. ISB N978-84-8049-559-2.

[15] Mehran R, Rao SV, Bhatt DL, Gibson CM, Caixeta A, Eikelboom J, Kaul S, Wiviott SD, Menon V, Nikolsky E, Serebruany V, Valgimigli M, Vranckx P, Taggart D, Sabik JF, Cutlip DE, Krucoff MW, Ohman EM, Steg PG, White H. Standardized bleeding definitions for cardiovascular clinical trials: a consensus report from the Bleeding Academic Research Consortium. Circulation. 2011 Jun 14;123(23):2736-47. doi: 10.1161/CIRCULATIONAHA.110.009449.

[16] Bellomo R, Ronco C, Kellum JA, Mehta RL, Palevsky P; Acute Dialysis Quality Initiative workgroup. Acute renal failure - definition, outcome measures, animal models, fluid therapy and information technology needs: the Second International Consensus Conference of the Acute Dialysis Quality Initiative (ADQI) Group. Crit Care. 2004;8(4):R204-12. doi:10.1186/cc2872.

[17] Jiménez D, De Miguel-Díez J, Guijarro R, Trujillo-Santos J, Otero R, Barba R, Muriel A, Meyer G, Yusen RD, Monreal M; RIETE Investigators. Trends in the management and outcomes of acute pulmonary embolism analysis from the RIETE Registry. J Am Coll Cardiol. 2016;67(2):162-70. doi:10.1016/j.jacc.2015.10.060.

[18] Pollack C V., Schreiber D, Goldhaber SZ, Slattery D, Fanikos J, O'Neil BJ, Thompson JR, Hiestand $B$, Briese BA, Pendleton RC, Miller CD, Kline JA. Clinical characteristics, management, and outcomes of patients diagnosed with acute pulmonary embolism in the emergency department: Initial report of EMPEROR (multicenter emergency medicine pulmonary embolism in the real world registry). J Am Coll Cardiol. 2011;57(6):700-6.

[19] Kabrhel C, Rosovsky R, Channick R, Jaff MR, Weinberg I, Sundt T, Dudzinski DM, Rodriguez-Lopez J, Parry BA, Harshbarger S, Chang $Y$, Rosenfield K. A multidisciplinary pulmonary embolism response team: initial 30-month experience with a novel approach to delivery of care to patients with submassive and massive pulmonary embolism. Chest. 2016;150(2):384-93. doi:10.1016/j.chest.2016.03.011.

[20] Klok FA, Van Kralingen KW, Van Dijk APJ, Heyning FH, Vliegen HW, Kaptein AA, Huisman MV. Quality of life in long-term survivors of acute pulmonary embolism. Chest. 2010;138(6):1432-40. doi:10.1378/chest.09-2482.

[21] Kline JA, Nordenholz KE, Courtney DM, Kabrhel C, Jones AE, Rondina MT, Diercks DB, Klinger JR, Hernandez J. Treatment of submassive pulmonary embolism with tenecteplase or placebo: cCardiopulmonary outcomes at 3 months: multicenter double-blind, placebo-controlled randomized trial. J Thromb Haemost. 2014;12(4):459-68. doi:10.1111/jth.12521.

[22] Vedantham S, Piazza G, Sista AK, Goldenberg NA. Guidance for the use of thrombolytic therapy for the treatment of venous thromboembolism. J Thromb Thrombolysis. 2016;41(1):68-80. doi:10.1007/s11239-015-1318-z.

[23] Kuo WT, Banerjee A, Kim PS, De Marco FJ, Levy JR, Facchini FR, Unver K, Bertini MJ, Sista AK, Hall MJ, Rosenberg JK, De Gregorio MA. Pulmonary embolism response to fragmentation, 
embolectomy, and catheter thrombolysis (PERFECT): initial results from a prospective multicenter registry. Chest, 2015; 148(3): 667-73. doi:10.1378/chest.15-0119.

[24] Piazza G, Hohlfelder B, Jaff MR, Ouriel K, Engelhardt TC, Sterling KM, Jones NJ, Gurley JC, Bhatheja R, Kennedy RJ, Goswami N, Natarajan K, Rundback J, Sadiq IR, Liu SK, Bhalla N, Raja ML, Weinstock BS, Cynamon J, Elmasri FF, Garcia MJ, Kumar M, Ayerdi J, Soukas P, Kuo W, Liu PY, Goldhaber SZ; SEATTLE II Investigators. A prospective, single-arm, multicenter trial of ultrasound-facilitated, catheter-directed, low-dose fibrinolysis for acute massive and submassive pulmonary embolism. JACC Cardiovasc Interv. 2015;8:1382-92. doi:10.1016/j.jcin.2015.04.020.

[25] De Gregorio MA, Guirola JA, Kuo WT, Serrano C, Urbano J, Figueredo AL, Sierre S, Quezada CA, Barbero $E$, Jiménez D. Catheter-directed aspiration thrombectomy and low-dose thrombolysis for patients with acute unstable pulmonary embolism: prospective outcomes from a PE registry. Int J Cardiol. 2019; 15;287:106-110. doi:10.1016/J.IJCARD.2019.02.061.

[26] Kesselman A, Kuo WT. Catheter-directed therapy for acute submassive pulmonary embolism: summary of current evidence and protocols. Tech Vasc Interv Radiol. 2017;20:193-6. doi:10.1053/j.tvir.2017.07.009.

[27] Ozmen C, Deniz A, Akilli RE, Deveci OS, Cagliyan CE, Aktas H, Celik Ai, Akpinar AA, Disel NR, Balli HT, Hanta I, Demir M, Usal A, Kanadasi M. Ultrasound accelerated thrombolysis may be an effective and safe treatment modality for intermediate risk/submassive pulmonary embolism. Int Heart J. 2016;57:91-5. doi:10.1536/ihj.15-271.

[28] Mostafa A, Briasoulis A, Telila T, Belgrave K, Grines C. Treatment of massive or submassive acute pulmonary embolism with catheter-directed thrombolysis. Am J Cardiol. 2016;117(6):1014-20. doi:10.1016/j.amjcard.2015.12.041.

[29] Tafur AJ, Shamoun FE, Patel SI, Tafur D, Donna F, Murad MH. Catheter-directed treatment of pulmonary embolism: a systematic review and meta-analysis of modern literature. Clin Appl Thromb. 2017;23:821-9. doi:10.1177/1076029616661414.

[30] Bhatt A, Al-Hakim R, Benenati JF. Techniques and devices for catheter-directed therapy in pulmonary embolism. Tech Vasc Interv Radiol. 2017;20:185-92. doi:10.1053/j.tvir.2017.07.008.

[31] Sista AK, Moriarty JM. The future of catheter-directed therapy: data gaps, unmet needs, and future trials. Tech Vasc Interv Radiol. 2017;20:224-6. doi:10.1053/j.tvir.2017.07.013.

[32] Fuller TJ, Paprzycki CM, Zubair MH, Hussain LR, Kuhn BA, Recht MH, Muck PE. Initial experiences with endovascular management ofsubmassivepulmonary embolism: is it safe?Ann Vasc Surg. 2017;38:158-63. doi:10.1016/j.avsg.2016.09.002.

[33] Chauhan CA, Scolieri SK, Toma C. Percutaneous pulmonary embolectomy using the FlowTriever Retrieval/Aspiration System. J Vasc Interv Radiol. 2017;28:621-3. doi:10.1016/j.jvir.2016.09.012.

[34] Zarghouni M, Charles HW, Maldonado TS, Deipolyi AR. Catheter-directed interventions for pulmonary embolism. Cardiovasc Diagn Ther. 2016;6:651-61. doi:10.21037/cdt.2016.11.15.

[35] Sharifi M. Systemic full dose, half dose, and catheter directed thrombolysis for pulmonary embolism. When to use and how to choose? Curr Treat Options Cardiovasc Med. 2016;18(5):31. doi:10.1007/s11936-016-0456-8.

[36] Bajaj NS, Kalra R, Arora P, Ather S, Guichard JL, Lancaster WJ, Patel N, Raman F, Arora G, Al Solaiman F, Clark DT 3rd, Dell'Italia LJ, Leesar MA, Davies JE, McGiffin DC, Ahmed MI. Catheterdirected treatment for acute pulmonary embolism: Systematic review and single-arm metaanalyses. Int J Cardiol. 2016;225:128-39. doi:10.1016/j.ijcard.2016.09.036.

[37] Meyer G, Vicaut E, Danays T, Agnelli G, Becattini C, Beyer-Westendorf J, Bluhmki E, Bouvaist H, Brenner B, Couturaud F, Dellas C, Empen K, Franca A, Galiè N, Geibel A, Goldhaber SZ, Jimenez $D$, Kozak M, Kupatt $C$, Kucher N, Lang IM, Lankeit M, Meneveau N, Pacouret G, Palazzini M, Petris A, Pruszczyk P, Rugolotto M, Salvi A, Schellong S, Sebbane M, Sobkowicz B, Stefanovic BS, Thiele $H$, Torbicki A, Verschuren F, Konstantinides SV; PEITHO Investigators. Fibrinolysis for 
patients with intermediate-risk pulmonary embolism. N Engl J Med. 2014;370 (15):1402-11. doi:10.1056/NEJMoa1302097.

[38] Hellenkamp K, Schwung J, Rossmann H, Kaeberich A, Wachter R, Hasenfuß G, Konstantinides S, Lankeit M. Risk stratification of normotensive pulmonary embolism: prognostic impact of copeptin. Eur Respir J. 2015;46:1701-10. doi:10.1183/13993003.00857-2015.

[39] Yusuff $H$, Zochios V, Vuylsteke A. Extracorporeal membrane oxygenation in acute massive pulmonary embolism: a systematic review. Perfusion. 2015;30:611-6. doi:10.1177/0267659115583377.

[40] Corsi F, Lebreton G, Bréchot N, Hekimian G, Nieszkowska A, Trouillet J-L, Trouillet JL, Luyt CE, Leprince $P$, Chastre J, Combes A, Schmidt $M$. Life-threatening massive pulmonary embolism rescued by venoarterial-extracorporeal membrane oxygenation. Crit Care. 2017;21:76. doi:10.1186/s13054-017-1655-8.

[41] Aizman A, Mercado M, Andresen M. Tromboembolismo pulmonar: Estratificación de riesgo y dilemas terapéuticos. Rev Med Chil. 2012;140:1482-9. doi:10.4067/S0034-98872012001100016.

\section{Material gehigarria}

\section{Edukien aurkibidea:}

\section{A. Aldagai askeak:}

A.1. Epidemiologikoak etaAdministratiboak ospitaleratzean

A.2. Aurrekari Pertsonalak

A.3. Tratamendu aurreko Kliniko-Analitikoak

A.4. Tratamendu aurreko Proga Osagarriak

A.5. Arrisku Eskalak

A.6. Tratamenduarekin erlazionatuak

A.7. Tratamendu osteko Kliniko-Analitikoak

A.8. Ospitaleko Altaren ondorengo Jarraipena

\section{B.Menpeko aldagaiak:}

\section{B.1. Ospitalekoak \\ B.2. Jarraipena}

\section{A. ALDAGAI ASKEAK:}

\section{A.1. Epidemiologikoak eta Administratiboak ospitaleratzean:}

Jaiotze-data, Sexua, DonostialdeaESIko Historia Klinikoaren zenbakia, Policlínica Gipuzkoako Historia Klinikoaren zenbakia, ZIUan Ospitaleratzea, Jatorria, Ospitaleratze-data, Ospitaleko Alta-data, ZIUan Ospitaleratze-data, ZIUtiko Alta-data, Aurretiko Ebakuntzaren Data, Ikerketatik Kanporatzea.

\section{A.2. Aurrekari Pertsonalak:}

Aurretiko sakoneko zain-tronbosia, Aurretiko BTEa, BTEaren Familia Aurrekariak, Sendagaiekin erlazionaturiko aurretiko BTEa, Aurretiko immobilizazioa (aurreko 30 egunetan), Gaixotasun Onkologiko Ezaguna, Aurretiko Ebakuntza (aurreko 30 egunetan), Aurretiko Ebakuntzaren Data, Profilaxia Enoxaparinarekin, Ohiko Antiagregazio Tratamendua.

\section{A.3. Tratamendu aurreko Kliniko-Analitikoak:}

Disnea, Sinkopea, Bularreko mina, Beheko Gorputz-adarretako zeinuak/sintomak, Sintomen Hasiera, Tratamendu aurreko BBG, Arteria-PresioSistolikoa, Bihotz-maiztasuna, Shock Index, Tratamendu 
aurreko Shock-a, Inotropoak/Basoaktiboak, T-Troponinaultrasentikorra, Pro-BNP, Arteriako Oxigeno Asetasuna, Oxigeno Ekarpena, Tratamendu aurreko intubazioa.

\section{A.4. Tratamendu aurreko Proga Osagarriak:}

Ekokardiografia transtoraziko (ETT) bidezko Eskuin Bentrikuluaren Disfuntzioa, TAPSEETTan, BAP sistolikoa ospitaleratzean (ETT), Sakoneko Zain-Tronbosia (SZT) (ECOdoppler), Sakoneko zaintronbosia arriskua (ECOdoppler), Tomografia konputerizatu (TK) bidezko BTEaren kokapena: Zentrala (bihotz barrukoa, birika-arteriaren enborrekoa, birika-arteria nagusietakoa) eta Periferikoa (lobarra edo segmentarioa), Tronboen Kokapena (TKn).

\section{A.5. Arrisku Eskalak:}

BTEaren Diagnostiko Estratifikatua (ESC 2014 Eredua), PESI Eskala, RIETE Hemorragia Eskala, CRUSADEHemorragia-ArriskuEskala, Fibrinolisirako Kontraindikazioak.

\section{A.6. Tratamenduarekin erlazionatuak:}

Egindako Tratamendua (bat ere ez, Antikoagulazio soila, FS, K-TFI, E-GKZ), Fibrinolitikoa, Fibrinolisidata, Biriketako Enbolektomia Ebakuntza (E-GKZ), E-GKZaren data, Biriketako Arteriografia, Kateter bidez gidatutako birika arteriako terapia farmakoinbasiboa (K-TFI), K-TFI-data, K-TFlaren hasierako eta amaierako APT sistolikoa, K-TFlaren hasierako eta amaierako AP diastolikoa,Birikaenbolektomiaren hasierako eta amaierako AP diastolikoa, K-TFlaren hasierako eta amaierako BAP sistolikoa, K-TFlaren hasierako eta amaierako BAP diastolikoa, K-TFlaren hasierako eta amaierako BM, K-TFlarekin erlazionaturiko konplikazioak, K-TFIrako sarbide baskularrarekin erlazionaturiko konplikazioak, Bihotzeko kirurgia mota, Bihotzeko kirurgiaren data.

\section{A.7. Tratamendu osteko Kliniko-Analitikoak:}

Hemorragia-mota (BARCBleedingAcademicResearchConsortiumconsensusdocument), HemorragiaArriskua, Beheko kaba zaineko (BKZ) iragazkiaren ezarpena, BKZeko iragazkiaren ezarpenaren data, TAPSE (ETT) ospitaletiko altan, BAP sistolikoa (ETT) ospitaletiko altan, TransfunditutakoHematien Kontzentratua, Aireztapen mekanikoa (AM) (orduak), Trakeotomiaren beharra, AMarekin erlazionatutako pneumonia, Giltzurrun gutxiegitasuna (AKIN), gorputzez kanpoko arazketa teknika (GKAT), Ospitaleko helmuga alta ondoren.

\section{A.8. Ospitaletiko Altaren ondorengo Jarraipena(6 hilabetera arte):}

Jarraipenerako Zerbitzu Medikoa, Jarraipenaren Data, Gradu Funtzionaleko Disnea - NYHA, Eskuineko bihotz gutxiegitasuna, Ezkerreko bentrikuluaren eiekzio-frakzioa (ETT), Eskuin bentrikuluaren disfuntzioa (ETT), BAP sistolikoa jarraipenean (ETT), TAPSE jarraipenean (ETT), Jarraipeneko bularreko angio-TK (hautatutako kasuetan), Tronbofilia-azterketa, Jarraipeneko D dimeroa, Tratamendu antikoagulatzailea (AK), Antikoagulazioarekiko jarrera, KKetatiko altaren data, Azken jarraipenaren data.

\section{B.MENPEKO ALDAGAIAK:}

\section{B.1. Ospitalekoak:}

Ospitaleko heriotza, Heriotzaren data, Heriotzaren zergatia, Hemorragiagatiko heriotza.

\section{B.2. Jarraipena:}

Heriotza azken jarraipenean,Ospitaleratzetik azken jarraipenerainoko biziraupena, Heriotzaren zergatia, BTEagatiko heriotza. 